Please do not remove this page

RMIT

UNIVERSITY

\title{
Virtual learning environments for time-stressed and peripatetic managers
}

Jones, Sandra; McCann, Jackie

https://researchrepository.rmit.edu.au/esploro/outputs/9921861824501341/filesAndLinks?institution=61RMIT_INST\&index=null

Jones, S., \& McCann, J. (2005). Virtual learning environments for time-stressed and peripatetic managers. Workplace Learning, 17(516), 359-369. https://doi.org/10.1108/13665620510606779

Document Version: Accepted Manuscript

Published Version: https://doi.org/10.1108/13665620510606779

Repository homepage: https://researchrepository.rmit.edu.au

(c) Emerald Group Publishing Limited

Downloaded On 2023/04/26 19:34:38 +1000

Please do not remove this page 
Academy of Management

Journal of Workplace Learning ISSN:1366-5626

Special Issue

E-Learning at the Workplace

Virtual Learning Environments forttime-stressed and Peripatetic Managers

Dr Sandra Jones

Associate Professor of Employment Relations

School of Management

RMIT

and

Jackie McCann

Change Management Consultant

Visiting academic

DBA candidate

School of Management

RMIT

Published as:

Jones, S. and McCann, J. (2005), 'Authentic situated learning environments-the flexible learning alternative for peripatetic managers in a global world of flexible workplaces' Journal of Workplace Learning - Special Issue of E-Learning at the Workplace, pp.359- 369

Citation:

Jones, S and McCann, J 2005, 'Virtual learning environments for time-stressed and peripatetic managers', Workplace Learning, vol. 17, no. 516, pp. 359-369.

Sj/mydocs/research/Journal/WL, E-learning at the Workplace, January 2005 


\section{Flexible Virtual Learning Environments for Peripatetic Managers}

\section{Abstract}

\section{Purpose}

The paper argues that virtual situated learning environments (VSLE), designed as authentic learning experiences, can provide the growing number of peripatetic managers with the opportunity to engage in collaborative learning opportunities.

\section{Methodology/Approach}

An action learning methodology, using first person observation of practice, is invoked. This first person observation is inclusive of the designers and facilitators of the VSLE (the authors), and of managers participating in the learning activities as students. This methodology was chosen in recognition of the need to qualitatively demonstrate, rather than quantitatively measure, the effectiveness of the VSLE in management education.

\section{Findings}

The findings suggest that on-line learning environment has, when designed effectively to supplement rather than replace face-to-face learning, significant advantages for the peripatetic manager.

\section{Research implications/limitations}

It is recognised that there are limitations in generalising from particular case studies, particularly when a first-person action methodology is undertaking. However, this needs to be weighed against the opportunity provided by this research method to present qualitative depth to the research, a characteristic particularly required when dealing in contemporary and intangible issues related to knowledge sharing.

\section{Practical implications}

The implications are that the on-line learning environment has, if appropriately designed and facilitated, and if combined with face-to-face learning opportunities, significant learning opportunities for peripatetic managers.

\section{Originality/value of paper}

The research has significant value for both peripatetic managers seeking to engage in learning environment and universities and academics seeking to provide learning opportunities that are both accessible to, and relevant for, the newly emerging peripatetic managers.

\section{Keywords}

Management learning environments; virtual situated learning environment; peripatetic managers 
Introduction

There is a plethora of change facing society as new interactive communication technology (ICT), underpinned by the world-wide-web, necessitates a fundamental reassessment of relationships between society, business and the political system (Allee 2002). Knowledge, its continual acquisitions and sharing, and its existence in both a tacit as well as an explicit form, is becoming recognised as the competitive advantage for business. Herzenberg, Alic \& Wial (1998, p.91) state that "communication of knowledge accelerates the achievements of economies of depth....transfer and sharing of knowledge holds considerable untapped potential for performance gains”. Zack (1999, p.125) claims that many organisations are recognising that to remain competitive they must manage their "intellectual resources and capabilities”.

The change requires multiple, intertwining forces of content, context and community (Seely Brown 1999). For business, for example, traditional definitions of the workplace as being a stable place in a single central location, with 'normal' daily hours confined to 9-5 daylight hours, is being replaced by global organisations (through globally positioned parts of the business, global outsourcing, and/or global supply chains) and global communication networks (email, global 'blogs', diaries, discussion boards etc), that both reduce traditional 'tyrannies of distance' and change notions of 'normal' daily hours of work. The new global workplace requires managers to work from a variety of global geographic locations (hotel rooms, planes, and home), and in a mix of time zones.

In addition to the challenges of the new global workplace, managers are being faced with a work environment that is increasingly uncertain, chaotic and ambiguous. The relationship between managers and employees is changing significantly as it is recognised that employees now 'own' the fundamental factor of production (or competitive advantage) [knowledge] and thus managers 'manage' by the consent of the workers not by controlling them.

This confluence of factors requires managers to reassess their roles and broaden their skills to assist them to manage diverse functions in disparate communities and cultures, and to share the knowledge gained from their practical experience. This requires continuous engagement in learning. 
In response to these needs, educational providers are realising the need to move beyond the "narrowly-based professional education that focuses on skills in particular practices” (Bowden \& Marton 1998, p.26). First, by designing new learning opportunities in which managers contribute, and reflect, upon their own observations of their professional practice. Biggs (1990) states:

\begin{abstract}
when the basic bodies of knowledge and knowledge relating to professional practice, are changing as rapidly as they are, it no longer makes sense to teach students all those things they will need to know in their professional careers....Students should be taught how to learn, how to seek new information, how to utlize it and evaluate its importance, how to solve novel, nontextbook, professional problems. They will need metacognitive skills, and an abstract body of theory on which to deploy them, so that they can judge reflectively
\end{abstract}

Second, educators are recognising the need to design educational opportunities that use the on-line environment to supplement (and in some instances replace) regular weekly face-to-face (F2F) attendance.

From the F2F to the on-line learning environment

Management educational, particularly in a university environment, has been traditionally structured around a 3-4 hourly weekly face-to-face class, compacted into a 'semester' over 12-13 weeks, with lengthy breaks between semesters. This structure was designed to meet the educational needs of full-time undergraduate students undertaking a number of courses (usually around 4 per semester) as part of management studies. It was then adapted with the addition of evening sessions to accommodate part-time practitioners seeking to undertake management studies. However, increasingly, this structure does not take account of the need to provide lengthier, more interactive networking opportunities, for managers. Nor does it take into account the work pressures on managers who often arrive for a weekly three hour class after a hectic stressful day/week [or they lose part of a weekend after a stressful working week]. Finally, it does not take account of the peripatetic managers in a global workplace with either or other lengthy periods of global work and travel commitments.

What is needed is the design of educational opportunities that address the structural, environmental and emotional pressures on managers, and, at the same time, provide opportunities for reflection and continuous learning over the longer term. This requires a new learning environment that encourages reflection on professional 
practice, enables managers to network in order that tacit knowledge is more readily recognised and shared, and caters for the physical needs of peripatetic managers. In other words, what is needed is a combination of a traditional educational learning environment in which knowledge is created and shared "for its own sake as well as the benefits that knowledge brings to the whole community” (Miller 2000, p.110), with a more 'entrepreneurial' learning environment in which managers are able to demonstrate to their employers immediate cost-benefit returns through observable improvements in their professional practice, as well long-term benefits as they share their new knowledge within the organisation.

This has been recognised by many private training organisations that have designed short, compressed, management knowledge sharing opportunities that often have a 'distance' education component. In order to bring theory and practice together, these learning opportunities are often designed around a well-known speaker who provides information on their experiences. These 'short courses' are effective in imparting information or hearing of the experiences of others, but they are less able to provide assistance with the more lengthy, introspective reflection learning opportunities that provide managers with opportunities for what many have called 'deep' learning and the continual creation and sharing of new knowledge.

Universities have also sought to accommodate the needs of practicing managers by changing the structure in which educational opportunities are offered. Evening classes, intensive weekend workshops, ‘distance’ educational opportunities have been provided. Universities have been experimenting with new learning environments in which academics combine their conceptual knowledge with that of practitioners, and through the use of experiential activities, extend the practitioners ability to analyse and reflect (Laurillard 1994). Various opportunities for practicing managers and professionals to share, analyse and reflect on their practice have been designed.

First, there is an increased emphasis on encouraging practitioners to become 'insider' researchers, to reflect upon their own, and others, practice in order to both recognize tacit knowledge contained within their heads, and to improve their practice (Edwards 2002; Schon 1983; 1987). Second, academics have designed Situated Learning Environments (SLE) that aim to reproduce real-life challenges found in many businesses. These SLEs' seek to incorporate Stein's (1998, p.1) view of learning as 
"essentially a matter of creating meaning from the real activities of everyday life". Thus SLEs provide opportunities for knowledge and skills to be learnt in a context that reflects how knowledge is obtained and applied in everyday situations. In so doing they address the possible limitations of 'insider' research in which the manager and professional has only their own practice to call upon (Jones et al 2004).

The SLEs can either present participants with professional practice challenges that are well-defined, with suggested responses embedded in the 'case study' design of the SLE (the Harvard Case Study method is one such example). Or, the SLE can be designed to provide professionals with a rudimentary knowledge of the case study organisation and a number of ill-defined problems that require professionals to consider various approaches and solutions.

More recently, experiments with the on-line environment have been undertaken. Despite criticism that the on-line learning environment has the potential to return learning to a more 'instructional' rather than didactic knowledge developing exploratory approach (Snowden 2001; Allee 2000), it does provide opportunities to design a learning environment in accord with the principles identified above. Unfortunately, however, faced with the pressure to become more financially focussed as entrepreneurial universities subject to the same rational economics as other such enterprises (McIntyre and Marginson 2000, p.67), many universities have focussed their attention on designing on-line learning opportunities that are 'cheaper' rather than used to add value to the educational experience. Educators have been asked to prepare notes for delivery on-line (much like the traditional distance education model) and they are being encouraged to prepare 'learning objects' that are then made freely available for anyone to deliver (with the implied threat that the tacit knowledge of academics-as-(professional)-teachers is of little value and no longer required). This has resulted, on the one hand, in only limited experimentation with how the on-line environment can be used for innovative and value-adding learning opportunities for manager. On the other hand, it has provided fewer opportunities for managers to use the learning environment to network, share their tacit knowledge, and embark in continuous learning because of the peripatetic nature of their work environment.

Accordingly, there is need for a fundamental reappraisal of how management learning opportunities can be re-designed for the on-line learning environment to enable 
managers to share their reflections on their practice, to network, and to cater for the newly peripatetic manager. The on-line learning environment provides potential to design different learning opportunities that increase the confluence between theory and practice in order to assist managers and practitioners to experience 'real-world' learning opportunities and to reflect upon their own experiences, in order to respond to continual change. Brown, Collins and Duguid, (1989) provide examples of how designing simulated real world situations through 'authentic learning opportunities' can provide opportunities for students to develop cognitive skills that require understanding of context and culture.

One such approach is to adapt SLE learning environments discussed above into a virtual SLE environment (VSLE). Professional practice activities associated with this VSLE can then be designed to be accessible by all managers at all times and from all parts of the global workplace. Several VSLEs designed by the authors are presented as examples in the next section, with assessment of the effectiveness of this learning environment provided by means of personal self-reflection of the authors and the participating managers.

\section{Virtual Situation Learning Environment (VSLEs)}

The focus in this section is on how the on-line environment can be used to design VSLEs in which managers both participate in professional practice activities designed as authentic learning opportunities, and also use the online environment to analyse, reflect on, network and discuss their experiences and learning. Our focus in designing the VSLEs was on assessing whether the on-line earning environment can assist managers, particularly those pressured by time and place, to engage in deep learning that is valuable both in the short and the long term. In both cases the VSLE's we designed complemented rather than replaced the F2F learning environment, and thus our conclusions can only relate to this mixed learning environment.

The authors, one an academic with management practitioner experience, and the other a practicing manager working as a visiting academic, designed the VSLEs as authentic learning environments in terms of the criteria identified by Reeves, Herrington and Oliver (2002, p.565). That is, they had real-world relevance and presented managers with problems that were complex, ill-defined and required participants to investigate problems from multiple perspectives. Although the period 
of time during which managers engaged in the on-line activity was short rather than sustained (over a week), given the nature of the negotiation and its setting within an ongoing employment scenario, the authors argue that environment did meet the criteria of being sustained over time. The activity also provided assessment that required the participating managers to reflect on their actions, beliefs, and values, and to integrate a number of different subject areas. Finally, the problem solving and assessment activities built into the learning environment required collaboration between the participants.

Another factor that the authors-as-designers took into account was that the professional practice activities associated with the VSEL had to be designed so that participants could contribute at any time of the day or night from anywhere in the world, at non-synchronous timing intervals.

The VSLEs were designed using a suite of interlinked, proprietary software suited to a range of teaching and learning approaches as part of the university distributed learning system (DLS) to which all students were linked. This system enables technology to be used to provide a diversity of educational experiences through online content and interactions with both peers and academics.

Both VSLEs used as examples to illustrate learning opportunities for peripatetic managers drew on an earlier SLE designed and used successfully for professional practice management education in the face-to-face learning environment by the academic author. It consisted of an organization designed as a restaurant complex with a number of outlets, and had been used particularly to assist managers develop their skills in negotiation within and between 'managers' and 'employees' in the various outlets, with a combination of intensive activities (full day workshops) more extended participation over a number of weeks.

Research methodology for evaluation

Given the innovative nature of this VSLE, and the lack of any existing framework by which to asses the value of this experience for managers (except the criteria identified by Reeves, Herrington and Oliver 2002, p.565 as mentioned above), the authors agreed to assess the value of the VSLE through an action research qualitative research methodology with an emphasis on first-person reflection by themselves and the 
participants. In this way they hoped to take advantage of the depth of feedback that accompanies a qualitative 'lived experience' to demonstrate the effectiveness of this environment for management and thus to extrapolate from this what was needed to ensure that this learning environment would be effective in the more virtual environment of peripatetic managers who have less opportunities to meet face-to-face.

The authors acknowledge that generalising from the specifics of two examples has inherent weaknesses, especially when first-person reflective practice is the chief research method. However the fast pace of change in on-line technologies, the need to advance thinking about innovative ways to meet the educational needs of peripatetic managers, and the difficulty of designing appropriate measures of intangible feedback, is sufficient justification in the eyes of the authors, of the use of this method.

\section{Example 1}

In the first example the authors designed a practice activity for practicing manager enrolled in a post-graduate course in negotiating skills. In this activity some participating managers were identified either as managers in each (of 6) restaurant outlets, and the rest were identified as employees (waiters or waitresses, bartenders, kitchen cleaners or chefs) or union representatives of employees. Adopting their assigned roles, participants were required to negotiate (in the virtual environment) an industrial dispute. The negotiation was scheduled to take place over a week during which face-to-face classes were cancelled, with a face-to-face session scheduled for the end of the week to firstly, finalise the negotiations, but secondly (and more importantly) to evaluate two things - what had been learnt from the experience for negotiating in a virtual environment, and, what had been learnt about using the on-line environment for educational purposes.

Feedback from participating managers was collected in a number of ways. First, in the face-to-face class at the end of the week of negotiations participants were asked to verbally comment on the learning experience. Second, participants were asked to write a reflection paper on the value, and limitations, of the on-line participation experience for their learning. Third, at the end of the semester, participants were asked to provide written evaluation and comments on the overall mix of face-to-face 
and on-line learning opportunities. The authors added their own observation and reflections on the educational outcomes to this feedback

Verbal feedback by participants in the face-to-face class was instructive. Most participating managers indicated that they had, surprising, adopted their roles very realistically as a 'real-world' experience. One student stated that she had become so involved that she accessed the DLS sight a number of times a day to see what new discussion had been added. The authors observed that participating managers had realistically adopted their roles, to the extent that it was difficult to get participants to step out of their roles during the face-to-face feedback session. All participating managers stated that they were surprised at the extent to which the experience made explicit to them a change that had occurred in their professional practice, the extent to which they were already engaged in negotiating in the on-line environment through the use of emails between the parties, of which they had not consciously been aware. Some participants also reflected on the fact that the experience made them aware of the limitations of negotiating in the virtual environment. Two groups of participants had in fact met face-to-face to address some issues rather than completing the negotiating exercise completely on-line.

Written feedback from participating managers was obtained from their personal reflection papers ${ }^{1}$. Many mentioned their personal learning on the new skill requirements needed for them to function effectively in an on-line environment. Indeed, one participant stated that he recognised how he uses his physical stature in negotiations, as he no longer had this physical presence in the virtual environment. The authors observed that the reflection papers were more self-reflective than had been the case in previous iterations of this professional practice activity. Although it is difficult to claim a direct cause-and-effect in this case, it is interesting that participating managers appeared to be more able, and prepared, to reflect on their own practice rather than the practice of other, as had been the case in previous iterations of this exercise.

Written feedback from participating managers was obtained at the end of the semester on the educational value of the mix of face-to-face and on-line learning environments

\footnotetext{
${ }^{1}$ The authors gained permission from the participating managers to reference these reflections for research purposes
} 
was instructive. Here there was an interesting mix of feedback Although most participants stated that they had obtained educational value from the on-line experience, they also claimed that the volume of communication that occurred over the week, described by one as a 'noise factor', created challenges for the busy manager seeking to fulfil their work activities and participate in the educational experience.

Based on this feedback the authors conclude that the VSLE and associated professional practice activities provides a realistic learning environment in which managers can network, share experiences, and develop new skills, from a number oif different locations and at a number of different times. Thus the VSLE provides a valuable learning environment for peripatetic managers. However, when designing such a VSLE care needs to be taken to structure the professional practice activities such that they were not overly time demanding, that they are confined to a particular time period (for example over a week), and that there is some opportunity for a more personalised relationship to develop (either face-to-face or a synchronised activity to can be scheduled)

\section{Example 2}

The second VSLE again took the concept of a restaurant outlet but in this case it was designed to underpin a post-graduate Leadership and Management Skills course that was to be delivered completely on-line, in Vietnam. Once again the restaurant industry was used, as it provided the opportunity to explore a common industry in a variety of cultural circumstances with professional practice activities designed to explore inter-cultural issues and differences associated with global workplaces. A further complicating factor in this case was the need to recognise and accommodate the educational experience of the participating managers, used to a much more didactic and teacher-centered educational environment (Jones and Sobiecki 2002).

The specific VSLE restaurant complex was designed as a company that had been established in one (European) country, taken over by a group from another country (USA), and was currently extending its outlets into a third country (Asian Region). The website provided students with background information about the company, its history, structure, the service it provides, the current environment which it faces, and its strategy for the future. Although broad in coverage the information provided 
requires a significant degree of interpretation by the participating managers and thus is different in form and intent from the more formal case-study approach that requires interpretation of a self-contained body of information, and enables practitioners to add their own experience. Finally, the VSLE was designed to enable additions and deletions so that overtime the organizations could become a 'living organisation' to reflect real-world changes.

A series of professional practice activities and assessment activities that link the theory (provided through notes and reference links to academic theory and literature), to practice, associated with this VSLE, were also designed. The professional practice activities require both individual action and group activity similar to that presented to managers and leaders by real life challenges. These activities link the theory provided by notes and literature (with reference links provided to on-line accessible reference material). For example, participants are asked to discuss, with each other through virtual discussion groups,. how the theories discussed might apply in the VSLE, or in their work environments. Participants are also required to undertake formal group assessment activities that link the VSLE to more formal presentation of notes on theory, by utilising the on-line group discussion facilities. One example designed into is for students to prepare, and deliver virtually, a leadership speech

Feedback from participants in this case was a little more difficult as, by the time it was delivered, a decision to have a mix of a face-to-face learning environment with local facilitators, and the on-line learning environment, had been made.

Feedback from the local facilitators has been more instructive. The course is the first delivered as part of an MBA in Vietnam. Feedback from both the facilitator and the Teaching and Learning Director has been that the VSLE has provided an effective common business context from which students can begin to explore Western Management concepts, especially in terms of how they may influence Asian management values in global businesses. The professional practice activities associated with the VSLE have provided participants, first, with the opportunity to experience a more student-centered approach to learning in which their own experiences are recognised as valuable opportunities for learning. Second, they provide a degree of consistency of experience given that the VSLE provides a common workplace setting. This consistency has allowed for relatively controlled 
conditions and has assisted participants, used to a less 'analytically critical' learning environment that is separate from their own real life working environment, to adopt a more critical approach.

Furthermore, the VSLE provides a written record of discussion between participants that is useful for later refer when assessing their own knowledge development. It also has provided valuable feedback to academics as to the nature of group discussions.

In summary, the two examples presented here, provide evidence of the educational value that can occur from designing VSLEs with professional practice activities related to the VSLEs. There is evidence that participating managers did value the real-world nature of the learning experience. There is evidence that participating managers did develop new knowledge about the nature of their activities in a knowledge world. There is evidence that the learning environment can be translated into different cultures. There is also evidence that managers can participate from global positions and at varying times. For management academics the VLSE thus provides the opportunity to offer a new educational design appropriate for a global workplace.

However, in presenting the advantages of a VSLE as a learning opportunity, it must be recognised that experience suggests that consideration should be given to designing the virtual learning environment with some face-to-face learning opportunities. However, given that the technology is continually being developed further, virtual opportunities that are close to face-to-face opportunities are not beyond the bounds of the possible.

\section{Conclusion}

In this paper we have argued that the on-line environment presents opportunities to design learning opportunities for all managers, and in particular peripatetic managers who are often denied access to learning opportunities because of their inability to attend in a single physical learning environment, to participate in educational opportunities. The experience of designing and delivering 'virtual' skills enhancing opportunities, and the positive feedback from participants and facilitators of these learning activities, suggest that such a learning innovative is possible. The VSLE has significant advantages over the on-line instructional learning approach that has to-date 
dominated university approaches in that it enables managers to extend their knowledge by reflecting upon their own practical experience and that of others. The examples presented demonstrate how a VSLE, accompanied by professional practice activities have been shown to have the potential to be used as a valuable learning platform.

The authors acknowledge that there are still challenges in developing such a learning approach but claim that as technology is further developed more opportunities to design and deliver such learning environments will develop. In so saying the authors claim that the VSLE learning environment lends itself to the peripatetic manager working in a global workplace as the professional practice activities can be self-paced (within boundaries of group activities) and they enable some degree of selfassessment. At the same time it provides these managers/professionals with opportunities to extend their familiarity and use of the on-line environment as a communication network and thus provides managers with a 'safe environment' to experiment with ways that technology may be used as a tool for managers and leaders of global businesses. 
References:

Allee, V. (2000), "E-learning is not knowledge management”, Linezine.com, http://www.linezine.com/2.1/features/vaenkm.htm. accessed 29.12.03.

Allee, V. (2002), The Future of Knowledge, Butterworth Heinemann, USA.

Biggs, J. (1999), Teaching for Quality Learning at University, Open University Press, London

Bowden, J. and Martin, F. (1998), The University of Learning, Kegan Paul, London.

Brown, J.S.; Collins, A. and Duguid, P. (1989), "Situated cognition and the culture of learning”, [Electronic version]. Educational Researcher, 18(1), pp.32-42, Jan.-Feb. http://www.astc.org/resource/educator/situat.htm. accessed November 11, 2001,

Coady, T. (2000), Why Universities Matter, Allen and Unwin, St Leonards, NSW.

http://www.aln/alnweb/journal/jaln_Vol1issue2.htm., accessed $28^{\text {th }}$ September 2000.

Edwards, B. (2002), “Deep insider research”, Qualitative Research Journal, Vol 2 No 1, pp.71-84

Herzenberg S.A; Alic J.A. and Wial H. (1998), New Rules for a New Economy, ILR, Ithaca, Cornell.

Jones,S. (2005a-forthcoming), "Using IT to Augment Authentic Learning Environments", Authentic Learning Environments, Ideas, USA

Jones, S. (2005b - forthcoming), "Search for a new identity-academics, studentcentered pedagogies and information communication technologies", RMIT Studies in Teaching and Learning Monograph, University Press, Melbourne.

Jones, S. (2002), "Knowledge management - organisations and universities as a learning community of practice”, Proceedings ICIT International Conferences, April, Melbourne.

Jones, S. and Sobiecki, P, (2002), "Student-centred learning and International Students”, Proceedings 6th Pacific Rim 1st year in HE Conference, New Zealand, July.

Laurillard, D. (1994), "Multimedia and the Changing Experience of the Learner:, Proceedings: Asia Pacific Information Technology in Training and Education Conference and Exhibition, pp.19-25, June

McIntyre S. and Marginson, S. (2000), "The university and its public" in Coady T. Why Universities Matter, Allen \& Unwin, St Leonards, NSW, pp.49-71

Miller S. (2000), "Academic Autonomy”, in Coady T. Why Universities Matter, Allen \& Unwin, St Leonards, NSW, pp.110-131.

Morgan, G. (1997), Images of the Organisation, Sage, Newbury Park, CA

Pedler, M; Burgoyne, J. and Boydell, T. (1991), The Learning Company, McGrawHill, London.

Schõn, D. (1983), The Reflective Practitioner. New York, Basic Books

Schon, D (1987), Educating the Reflective Practitioner, Jossey-Bass, San Francisco.

Seely Brown, J. and Duguid, P. (2000), “Organisational learning and communities of practice: towards a unified view of working, learning and innovation”, Lesser, E; Fontaine, $\mathrm{M}$ and Slusher, J (eds.) Knowledge and Communities, pp.99-122, Butterworth-Heinemann, Massachusetts

Senge, P. (1990), The Fifth Discipline: the Art and Practice of the Learning Organisation, Doubleday, Currency, NY.

Snowden, D (2001), “The Intranet as a Complex ecology”, Content Management Review, February 2001, pp.1-6.

Zack M. (1999), "Developing a Knowledge Strategy”, California Management Review, Vol 41 No 3 Spring, pp. 125-145 